\title{
Evaluating a Large-Scale School Intervention Project in South Africa: Lessons and Challenges
}

\author{
Anil Kanjee \\ Research Professor, Tshwane University of Technology, South Africa \\ KanjeeA@tut.ac.za \\ Harbans Bhola \\ Research Fellow, Tshwane University of Technology and Professor Emeritus, \\ Indiana University, USA
}

\section{Doi:10.5901/mjss.2014.v5n23p792}

\begin{abstract}
This paper reports on the evaluation process and outcomes of a large-scale school intervention project conducted in South African schools. Known as the Quality Learning Project (QLP), the project intervened simultaneously at the district, school and classroom levels of the education system, focussing on achieving substantial improvements in learner performance. Two strategies of interventions were selected: capacity building to improve the functioning of districts, schools and classrooms; and effective teacher support to improve learning. A combination of quantitative and qualitative methodologies and indicators were utilized to build greater confidence in the results. The findings indicate that improvements in learner performance can be attributed to the interventions. The paper highlights emerging lessons from the evaluation of the QLP for efforts to improve the quality of education in South Africa.
\end{abstract}

Keywords: Quality learning project, large-scale evaluation, learner performance, path analysis

\section{Introduction}

Following the first democratic election in 1994, the new post-apartheid government enacted a number of policies that were intended to improve access to, and quality of, education provided to all South African children irrespective of race, gender, creed, socio-economic status and geographical location. This commitment was captured in the new Constitution and the Bill of Rights (Republic of South Africa, 1996a) which guaranteed the right to basic education for all children from age 7 to 15. Flowing from the new constitution, a number of major policies and acts were legislated in South Africa including the South African Qualifications Authority (SAQA) Act in 1995, the South African Schools Act (SASA) and the National Education Policy Act (NEPA) in 1996, the Basic Conditions of Employment Act, the Higher Education Act, the Further Education and Training Act in 1997, and the National Norms and Standards for School Funding and Employment of Educators Act in 1998. Collectively these measures were intended to create a national system of education to unite the previously fragmented, racially and ethnically divided education systems and to work toward the twin imperative of quality and equity in education (Sayed and Kanjee, 2013). This period also saw the emergence of new structures as well as new role-players and authoritative bodies to improve the quality of education in the country Parker (2002).

The process of transforming the education system at the policy level was accompanied by a variety of education quality improvement programmes and projects implemented at different levels of the system. Funded by government, international donors and/or the business community, these programmes and projects sought to support the state to address the challenge of providing quality education for all in South Africa. Most notably, these include the Thousand Schools Project (Mouton, 1999), Education Quality Improvement Program (Meyer, 2000), the District Development Support Program (DDSP/RTI, 2003), the IMBEWU Program (ECDoE, 2000), the Learning for Living Project (Schollar, 2008) and the Quality Learning Project (Kanjee and Prinsloo, 2005). However, to date there has been no comprehensive review of the various projects and limited discussion on the effect of the different intervention programs on the education system. Sayed, Kanjee and Nkomo, (2013) note that while a great deal of knowledge and a wealth of experience pertaining to school reform and education change initiatives has been accumulated since the early 90's in South Africa, there has been few attempts to systematically consolidate this knowledge and experience and to extract good practices that would contribute to the national discourses on education quality. In response to the dearth of reflective accounts of 
change, this paper reports on the evaluation process and outcomes of the Quality Learning Project (QLP), which in the context of school improvement programs in South Africa at the time, broke new ground in its approach, comprehensiveness and rigour. The paper begins by providing an overview of the QLP highlighting changes in the design and evaluation framework across the span of the project. Thereafter the paper discusses the effects of the QLP at the district, school and classroom levels concluding with a number of emerging lessons and its implications for efforts to improve the quality of education in South Africa.

\section{An Evolving Project Design and Evaluation Framework}

The Quality Learning Project (QLP) was a public-private partnership between the Business Trust and the Department of Education (DoE) that was initiated in 1999, and stemmed from the national commitment to providing education of good quality for all, particularly those who have been historically disadvantaged. It was a five year multi-level, multi-site education intervention implemented from 2000 to 2004 with the specific aim of improving learner performance in low performing schools across all nine provinces in South Africa, i.e., Eastern Cape, Free State, Gauteng, KwaZulu-Natal, Mpumalanga, North West, Northern Cape, Limpopo, and Western Cape. Mathematics and language were identified as the foundation for all further learning with teachers as the key actors for improving learner skills in mathematics, reading and writing. In order to ensure that schools obtained effective support and monitoring from district offices and that good practices gained from the project would be institutionalised, the program also focused on the development of district systems and staff as well as the school system and school management teams. The project was managed by JET Education Services (JET) and implemented by a consortium of eight education service providers responsible for the different intervention programs identified across the participating districts and schools (Kanjee \& Prinsloo, 2005).

The five key outcomes to be achieved at the end of the project were: (a) Improved learning outcomes in the languages of instruction and mathematics in Grades 8-12 as measured by a $10 \%$ improvement in mean overall matriculation examination pass rate; a 10\% improvement in mean matriculation mathematics pass rate; and a 10\% improvement in mean English Second Language matriculation pass rate ${ }^{1}$, (b) Improved teaching of languages and mathematics; (c) Improved governance and management; (d) Improved management of district offices; and (e) Improved support to schools by district offices (Prew \& Shar, 2013).

In the context of quality intervention programs in South Africa, the QLP broke new ground in including a monitoring and evaluation component as an integral part of its project implementation strategy, and for commissioning an independent external agency, the Human Sciences Research Council, to conduct the evaluation. The purpose of the evaluation was to provide relevant information to the project managers and service providers for the development, implementation and evaluation of interventions at the different levels of the system. Thus, the evaluation design and methodology comprised a baseline survey (2000) before the project interventions were implemented, a mid-term evaluation (2002) to review progress of the project, and a summative evaluation (2004) to determine whether the identified project aims and objectives were achieved (Kanjee \& Prinsloo, 2005).

The framework for the baseline evaluation conducted in 2000 was derived from the project proposal developed by the project managers and approved by project funders. The framework was based on the input-process-output model (Shavelson, McDonnell and Oakes, 1989) that was modified to address the unique aspects of the QLP, namely, the focus on districts, schools and classroom; the inclusion of the QLP intervention programmes; and the evaluation component. The framework also served as the basis for: (a) the deriving relevant indicators from the five key project outcomes, (b) the development of instruments, (c) the collection of data and (d) the analysis and reporting of results.

\subsection{Research design and analysis}

The research design for the QLP evaluation included both qualitative and quantitative approaches to provide scope for verification (of site visit observations) and triangulation (to survey responses). Owing primarily to financial considerations, data collection could not take place in all the schools. Thus a sampling strategy was adopted to ensure that information was obtained from all participating QLP districts while a representative sample of schools were selected from each district. 102 schools, representing approximately $20 \%$ of the QLP schools, were selected across all districts for the survey component while 36 of the sampled schools were selected for the site visit component (Table 1). The instruments developed for collecting data from project participants included district official, school principal and teacher interview

1 The matriculation examination is a high stakes external examinations intended to certify successful completion of 12 years of schooling for all South African learners. It is also use for admissions into higher education institutions. 
schedules and questionnaires as well district, school and classroom observation schedules. In addition, both questionnaires and tests (in mathematics and English second language) were administered to a sample of Grade 9 and Grade 11 learners, randomly selected across each grade to report on learner levels of performance in all sampled schools. While it was considered necessary to include control schools in the evaluation, no comparable schools could be identified as the QLP proposal required all schools from the identified districts to participate in the project.

Table 1: Realised sample of schools across QLP districts²

\begin{tabular}{|c|c|c|c|c|c|}
\hline Province/Districts & $\begin{array}{c}\text { Number of QLP } \\
\text { schools }\end{array}$ & $\begin{array}{c}\text { Survey sample } \\
\text { in } 2000\end{array}$ & $\begin{array}{l}\text { Site-visit sample } \\
\text { in } 2000\end{array}$ & $\begin{array}{l}\text { QLP sample in } \\
(2002) / 2004\end{array}$ & $\begin{array}{l}\text { Control schools } \\
(2002) / 2004 \\
\end{array}$ \\
\hline Eastern Cape & 21 & 1 & 1 & (2) 2 & - \\
\hline Lusikisiki & 31 & $\frac{1}{5}$ & $\begin{array}{l}1 \\
3\end{array}$ & (2) 3 & - \\
\hline Flagstaff & $\begin{array}{l}31 \\
37\end{array}$ & $\begin{array}{l}5 \\
7\end{array}$ & $\begin{array}{l}3 \\
3\end{array}$ & (3) 3 & - \\
\hline Libode & & & & & - \\
\hline \multicolumn{6}{|l|}{ Free State } \\
\hline Thabo & 29 & 6 & 2 & (4) 4 & (3)3 \\
\hline \multicolumn{6}{|l|}{ Mofutsanyana } \\
\hline \multicolumn{6}{|l|}{ Gauteng } \\
\hline Johannesburg South & 39 & 4 & 2 & (4) 4 & (3)3 \\
\hline Mega & 27 & 4 & 2 & (4) 4 & - \\
\hline \multicolumn{6}{|l|}{ Sedibeng West } \\
\hline \multicolumn{6}{|l|}{ KwaZulu-Natal } \\
\hline Inanda & $\begin{array}{l}21 \\
27\end{array}$ & $\begin{array}{l}4 \\
6\end{array}$ & $\begin{array}{l}2 \\
2\end{array}$ & $\begin{array}{l}\text { (3) } 3 \\
\text { (4) } 4\end{array}$ & - \\
\hline Ixopo & 27 & 6 & 2 & (4) 4 & - \\
\hline \multirow{2}{*}{\multicolumn{6}{|c|}{ Mpumalanga }} \\
\hline & 32 & 10 & 2 & (4)4 & - \\
\hline \multirow{2}{*}{\multicolumn{6}{|c|}{ North West }} \\
\hline & 31 & 3 & 2 & & \\
\hline Mafikeng & 36 & 12 & 2 & $\begin{array}{l}\text { (5) } 4 \\
\text { (5) }\end{array}$ & - \\
\hline Zeerust & & & & & (4)3 \\
\hline \multicolumn{6}{|l|}{ Northern Cape } \\
\hline Karoo & 32 & 0 & 2 & $(4) 4$ & - \\
\hline \multicolumn{3}{|l|}{ Limpopo } & 3 & (4) 4 & (1) 1 \\
\hline Bolobedu & 36 & 6 & 2 & (5) 5 & (2) 1 \\
\hline Konekwena & 24 & 6 & 2 & (2) 2 & (1) 1 \\
\hline \multicolumn{6}{|l|}{ Western Cape } \\
\hline Western Cape Metro & 34 & 6 & 2 & (5) 5 & - \\
\hline \multicolumn{6}{|l|}{ East } \\
\hline Total & 514 & 102 & 36 & (67) 66 & (14) 12 \\
\hline
\end{tabular}

The indices constructed in this study were based on information collected through questionnaires, observations, and interviews to report on the key outcomes and indicators identified to the project. Data was also obtained from all service providers pertaining to the nature and type of interventions implemented while results of the matriculation results for 2000, 2002, and 2004 were obtained from the Department of Education. Data analysis was conducted in three phases: (i) the creation of relevant indices; (ii) the production of frequencies and cross-tabulations; and (iii) correlations and path analysis modelling to determine the impact of the intervention programmes on the functioning of districts, schools, and classroom. All indices were aggregated by district, were reported in the form of tables or graphs, and included a brief description of the method of how the index was calculated. In addition, indicator scores were also grouped into categories of performance to compare levels of functioning from 2002 and 2004. In those instances where corresponding data was available from the baseline, the 2000 indices were also reported to provide a basis for comparison.

\footnotetext{
2 The disproportionate sample of schools for some districts was a result of the restructuring that occurred in these districts after data
} collection was completed. 


\subsection{Revised project design and evaluation framework (2002 to 2004)}

The results of the baseline evaluation carried out in 2000 revealed a discrepancy between the interventions of the different services providers that either were planned or were implemented at the district, school, and classroom levels, and highlighted the lack of alignment between the evaluation framework and the intervention framework. As a result, four key changes were made. First, an implementation framework was developed to ensure that all QLP interventions were aligned towards attaining the key project outcomes. This framework specified that "If the demands (to perform better) on the school and teacher are increased and we enable the district to provide high quality support to the school and we train the School Governing Boards (SGB's) and School Management Teams (SMT's) to manage their schools more effectively and we train the teachers to teach mathematics and the languages better, then we should get improved teaching quality in the classrooms which will lead to improved learner performance" (Kanjee \& Prinsloo, 2005, p. 1).

Second, the expected outcomes at the district, school and classroom (teacher) levels were redefined to align with the implementation framework and to ensure greater coherence between these three levels. Specifically, the outcomes sought to operationalise effective functionality at the district, school and classroom levels. For example, the functionality of an effective district was defined as effective district planning, effective human resources management, effective organisational development planning, effective support to schools and effective school monitoring. Similarly, functionality outcomes were defined for the school and classroom levels while key indicators and relevant covariates for each outcome were also identified (See Tables 2a to 2c).

Table 2a: Outcomes and indicators of functionality at the district level

\begin{tabular}{ll}
\hline Outcomes & Key Indicators \\
\hline Effective district planning & - Within district planning for development \\
& - School support planning \\
& - Implementation of support plans \\
& - In-school support of School Management Teams (SMTs) and educators \\
\hline Effective human resources management & - Existence and use of organograms \\
& - Existence and use of job description \\
& - Performance appraisal * \\
\hline \multirow{3}{*}{ Effective organisational development planning } & - Effective financial planning \\
& - Asset management* \\
\hline Effective support to schools & Effective curriculum planning* \\
\hline & - Provision of learner support material (LSM) and curriculum statements \\
Effective school monitoring & - Effective monitoring of learner performance \\
& - Use of learner-performance data \\
& - Existence and quality of school monitoring plans \\
\hline \multirow{2}{*}{ Covariates } & - Categorisation of schools \\
& - School finance monitoring \\
\hline
\end{tabular}


Table 2b: Outcomes and indicators of functionality at the school level

\begin{tabular}{ll}
\hline Outcomes & Key Indicators \\
\hline $\begin{array}{l}\text { More effective school } \\
\text { development planning }\end{array}$ & $\begin{array}{l}\text { Existence and effectiveness (participation of parties and core issues reflected) of school } \\
\text { development plans (SDPs) }\end{array}$ \\
\hline $\begin{array}{l}\text { Improved school } \\
\text { governance }\end{array}$ & Existence and functionality (minutes and matters addressed) of SGBs and SMTs \\
\hline $\begin{array}{l}\text { More effective HR } \\
\text { management }\end{array}$ & Meeting mathematics and language(s) of learning and teaching (LOLT) teacher-development needs \\
\hline $\begin{array}{l}\text { More effective } \\
\text { curriculum management }\end{array}$ & $\begin{array}{l}\text { Curriculum quality assurance (management); structures / procedures for planning learning } \\
\text { programmes; monitoring of learning programmes; existence of syllabi/learning programmes / } \\
\text { curriculum statements; monitoring of assessment practices }\end{array}$ \\
\hline $\begin{array}{l}\text { More effective school } \\
\text { administration }\end{array}$ & $\begin{array}{l}\text { Effective records of learning equipment and LSMs, learner/staff attendance, and learner } \\
\text { performance; policy/procedures for handling LSMs and assets; records/functionality of facilities and } \\
\text { equipment; financial management; planning documents }\end{array}$ \\
\hline Covariates & Indicator \\
\hline Profile of principals & Principal proficiency (experience, qualifications) \\
\hline $\begin{array}{l}\text { Physical resourcing } \\
\text { Adequacy of resources (media/communication, basic and LSMs); condition of facilities; condition of } \\
\text { infrastructure }\end{array}$ \\
\hline Support received & Parent/community participation; training, visits and LSM provision by DoE and others \\
\hline Classroom adequacy & $\begin{array}{l}\text { Class sizes; sufficiency of space; effect of shortages of instructional materials on teaching and } \\
\text { learning }\end{array}$ \\
\hline $\begin{array}{l}\text { Access to resources } \\
\text { learners) }\end{array}$ & \begin{tabular}{l} 
Learning and teaching materials, e.g. textbook, calculators. \\
\hline
\end{tabular} \\
\hline
\end{tabular}

Table 2c: Outcomes and indicators of functionality at the classroom level

\begin{tabular}{|c|c|}
\hline Outcomes & Key Indicators \\
\hline $\begin{array}{l}\text { More effective management and delivery of } \\
\text { learning programmes }\end{array}$ & $\begin{array}{l}\text { Existence of learning programmes and lesson plans } \\
\text { Structure of learning plans and lesson plans } \\
\text { Adherence to and coverage of learning programmes } \\
\text { Quality of learning programmes and lesson plans } \\
\text { Curriculum coverage }\end{array}$ \\
\hline Delivery of learning programmes & $\begin{array}{l}\text { Appropriate level of cognitive demand } \\
\text { Lesson pedagogy: types of questions } \\
\text { Lesson coherence }\end{array}$ \\
\hline Improved assessment practices & Type and frequency of assessment practices \\
\hline More effective use of LSMs & Teachers' access to and use of LSMs \\
\hline Improved learner participation & $\begin{array}{l}\text { Quality and quantity of teacher questions } \\
\text { Quality and quantity of learner responses } \\
\text { Learner engagement in the classroom } \\
\text { Learner engagement outside the classroom }\end{array}$ \\
\hline Covariate & $\begin{array}{l}\text { Teacher profile } \\
\text { Teacher time on task } \\
\text { Learner attitudes to learning, } \\
\text { School and the management climate } \\
\text { Class size } \\
\text { Availability of teaching and learning resources }\end{array}$ \\
\hline
\end{tabular}

Third, the evaluation framework was amended to report on the revised outcomes and indicators while the methods and design for the evaluation study was extended to include control schools and site visits to all sampled schools. Specifically, the initial sample of 102 experimental schools selected for the baseline study was reduced to 70 while 16 control schools were added from four QLP districts. This revision was only made possible due to changes in the selection of participating schools, that is, in some districts, a number of selected schools were excluded. In the initial agreement, all schools in participating districts were identified to receive the interventions, thus eliminating the possibility of selecting any control schools. While the possibility of selecting control schools from other district was considered, this option was eventually dropped given that the large variations between districts rendered it difficult to identify any matching control schools. No 
changes were made regarding the district office site visits. The site visits to schools included classroom observations, teacher and principal interviews as well as a review and collection of relevant documents (See Table 1 for revised sample). Realized samples of the different groups that became foci for the evaluations of 2002 and 2004 are reported in Table 3. While all instruments were updated to align with the new indicators and revised evaluation design, wherever possible questions were left unaltered to allow for comparison to the baseline data. For learners in the sample schools, no changes were made to the questionnaires and tests (in mathematics and English as second language) that were administered to the sample of Grade 9 and Grade 11 learners.

Table 3: Realised sample for mid-term and summative evaluations

\begin{tabular}{lcccc}
\hline Target group & QLP 2004 & QLP 2002 & Control 2004 & Control 2002 \\
\hline Learners & 2033 & 2067 & 368 & 430 \\
Teacher questionnaires & 271 & 259 & 48 & 46 \\
Class observations & 403 & 405 & 79 & 84 \\
School principals & 66 & 67 & 12 & 14 \\
Circuit managers & 39 & 29 & - & - \\
District managers & 15 & 17 & - & - \\
Mathematics learning area specialists & 11 & 15 & - & - \\
Language learning area specialists & 11 & 13 & - & - \\
\hline
\end{tabular}

Fourth, the initial learning outcomes measures, that is, a $10 \%$ improvement in mean overall matriculation pass rate; a $10 \%$ improvement in mean mathematics pass rate; and a 10\% improvement in mean English Second Language pass rate, were also revised. It was acknowledged that pass rates, when used as sole indicators, could be problematic as small increases from low baselines (previous poor matriculation results) could appear as large improvements. Moreover, schools could artificially inflate Grade 12 pass rates by holding back potentially unsuccessful Grade 11 learners or by requiring learners to take subjects at the less academically demanding standard grade level. Consequently, these targets were refined using stringent criteria that more reliably reflected school-performance outcomes. These categories were: (a) an increase in the absolute number of learners passing, and with English Second Language at the Higher Grade (HG) level, as an indication of the quantitative improvement of learner results; (b) an increase in the number of learners passing with university exemption (that is a pass rate which qualifies a candidate to apply for university admission), and with mathematics at HG, rather than Standard Grade, as an indication of an improvement in quality of the learner results; and (c) an increase in overall matriculation pass rate, as an indication of improved efficiency in learner results.

\section{Improvements in Learner Performance in the QLP3}

Table 4 provides information on changes in Grade 12 learner performance in the QLP and control schools, that is, the increase or decrease between 2000 and 2004, aggregated by province. Grade 12, being the apex of school level education, gives an in-depth perspective on change in the schooling system. In the first line, against EC (Eastern Cape Province), are included, in dual-entry columns, the numbers 53 and 10.3 which indicate an increase of 53 learners in the Eastern Cape QLP schools, between 2000 and 2004, who passed their matriculation exams representing a 10.3\% increase. Similarly, the next dual-entry column lists the increase in the number of learners (35) and the corresponding percentage (14.5\%) who qualified for university admission from the Eastern Cape QLP schools. Similar figures are provided for pass rates for English HG, Mathematics HG and Mathematics SG and the overall pass rate. It should be noted that in Mpumalanga (MP) changes from 2000 to 2004 in overall pass rates represent a decrease of 49 learners while the Mathematics HG results in Free State (FS), Limpopo (LM) and Western Cape (WC) all increased from a baseline of zero. Differences between the QLP and control schools are also presented. In the first row (Q > C4), the numbers and percentages pertaining to learners from all QLP schools in the nine provinces are compared to the controlschool figures from the four provinces, while in the second row (Q4 > C4), comparisons are to the four QLP districts from which both experimental and control schools were sampled.

3 While the QLP spanned a period of five years from 2000 to 2004, it consisted of two integrated and layered exercises: from 2000 to 2001 and 2002 to 2004 as distinguished by the evaluation and interventions conducted before and after the adoption of an integrated implementation and evaluation framework. The evaluation reported here is that conducted during 2002-2004, which was enriched by the lessons learned during 2000-2001. 
Table 44: Change in Grade 12 learner performance between 2000 and 2004 across QLP and control schools by province

\begin{tabular}{|c|c|c|c|c|c|c|c|c|c|c|c|c|}
\hline \multirow{2}{*}{ Province /Group } & \multicolumn{2}{|c|}{ Overall passes } & \multicolumn{2}{|c|}{ University exemptions } & \multicolumn{2}{|c|}{ English HG } & \multicolumn{2}{|c|}{ Maths HG } & \multicolumn{2}{|c|}{ Maths SG } & \multicolumn{2}{|c|}{ Overall pass rate } \\
\hline & No & $\%$ & No & $\%$ & No & $\%$ & No & $\%$ & No & $\%$ & $\%$ pts & $\%$ \\
\hline \multicolumn{13}{|c|}{ QLP Schools } \\
\hline EC & 53 & 10.3 & 35 & 145.8 & 9 & 0.8 & 14 & 1400.0 & 159 & 47.2 & 11.5 & 38.7 \\
\hline FS & 78 & 147.8 & 19 & 271.4 & 5 & 2.7 & 1 & - & 32 & 266.7 & 39.1 & 222.1 \\
\hline GP & 206 & 46.5 & 84 & 158.5 & 262 & 40.5 & 31 & 1033.3 & 40 & 31.3 & 20.8 & 41.7 \\
\hline KZN & 111 & 28.3 & 39 & 58.2 & 274 & 63.4 & 0 & - & 126 & 92.7 & 23.3 & 56.1 \\
\hline MP & -49 & -28.7 & -8 & -42.1 & -38.0 & -57.2 & 0 & - & 8 & 24.2 & 3.2 & 9.5 \\
\hline NW & -53 & -16.8 & -11 & -33.3 & 39 & 8.4 & 15 & 500.0 & 43 & 38.4 & -1.5 & -2.8 \\
\hline NC & -19 & -14.4 & 10 & 90.9 & -36 & -22.1 & 1 & 20.0 & -3 & -9.4 & 22.1 & 35.2 \\
\hline LM & -57 & -9.3 & 25 & 21.7 & 177 & 24.0 & 8 & - & 71 & 77.2 & 12.6 & 24.1 \\
\hline WC & 135 & 39.5 & 1 & 3.5 & 214 & 54.2 & 11 & - & 115 & 155.4 & 18.4 & 36.9 \\
\hline All QLP & 405 & 13.6 & 194 & 54.3 & 564 & 11.8 & 81 & 324.0 & 591 & 61.8 & 15.7 & 37.1 \\
\hline 4 QLP & 174 & 12.2 & 117 & 56.3 & 483 & 23.8 & 55 & 916.7 & 186 & 54.1 & 15.5 & 32.0 \\
\hline \multicolumn{13}{|c|}{ Control Schools } \\
\hline FS & -24 & 12.1 & 6 & 11.8 & -182 & -47.5 & -5 & -15.2 & 18 & 26.9 & 25.8 & 63.5 \\
\hline GP & 71 & 16.7 & 12 & 10.9 & 390 & 153.5 & -19 & -24.7 & 133 & 114.7 & 5.2 & 7.7 \\
\hline NW & -84 & 26.4 & -40 & -40.8 & -337 & -92.6 & 4 & 17.4 & 26 & 20.5 & -2.1 & -2.7 \\
\hline LM & -13 & -9.0 & 6 & 20.0 & -16 & -8.8 & 10 & - & 5 & 16.1 & 31.3 & 71.0 \\
\hline 4 Contr & -50 & -4.6 & -16 & -5.5 & -145 & -12.3 & -10 & -7.5 & 182 & 53.4 & 13.9 & 23.8 \\
\hline \multicolumn{13}{|c|}{ Differences between QLP and Control-school Performances } \\
\hline$Q>C 4$ & 455 & 18.2 & 210 & 59.9 & 709 & 24.1 & 91 & 331.5 & 409 & 8.5 & 1.8 & 13.4 \\
\hline Q4 > C4 & 224 & 16.8 & 133 & 61.8 & 628 & 36.0 & 65 & 924.2 & 4 & 0.7 & 1.5 & 8.2 \\
\hline
\end{tabular}

While assertions of causality cannot be made, based on the data reported in Table 4, some statements of a correlative nature can be made based on the summary data presented in Table 5 . In analyzing the data, it should be noted that the extremely high percentage differences for Mathematics HG (924\%) is due to the very low number of learners passing in the baseline survey conducted in 2000, while the low difference noted for Mathematics SG (0.7\%) can be attributed to the fact that QLP schools were discouraged from enrolling learners for Mathematics SG. Read together, Tables 4 and 5 clearly show that initial project objectives were met almost without exception.

Table 5: Indicators at Grade 12 level of the success of the QLP (from 2000 to 2004)

\begin{tabular}{lc}
\hline \multicolumn{1}{c}{ Key indicators at school level (Grade 12) } & $\begin{array}{c}\text { Percentage points by which improvement in QLP } \\
\text { schools is higher than in control schools }\end{array}$ \\
\hline Quantity of output & 16.84 \\
Learners passing matriculation examinations & 36.03 \\
Learners passing English Second Language (HG) & 61.79 \\
\hline Quality of output & 924.19 \\
Learners passing with university exemption & 0.70 \\
Learners passing mathematics (HG) & \\
Learners passing mathematics (SG) & 8.20 \\
\hline Efficiency of output & \\
Overall school matriculation pass rate & \\
\hline
\end{tabular}

\section{Improved System Functioning in the QLP}

An important part of the QLP programme evaluation was to examine its effects on the functioning of districts, schools, and classrooms and are described below.

${ }^{4}$ EC stands for Eastern Cape; FS for Free State; GP for Gauteng; KZN for KwaZulu-Natal; MP for Mpumalanga; NW for North West; NC for Northern Cape; LM for Limpopo; and WC for Western Cape. 


\subsection{District-level functioning changes}

A district education office is meant to have two primary education effects on teaching and learning. The first is to hold schools accountable by setting targets and monitoring their performance against these targets; and the second is to provide, whenever necessary, the needed support to assist schools to meet the targets. The capacity of the district office as defined by its human and physical resource profiles was also analysed, on the assumption that capacity is a prerequisite for the provision of effective monitoring and support services to schools. While the human and physical resource profiles were treated as covariates, which are background factors against which to understand the dynamics of the district offices, the effectiveness of the district is gauged against the primary expected outcomes of the QLP at the district level.

Changes in the levels of functioning of district offices reported here cover the period from 2002 to 2004, and were calculated as the score differences obtained in 2004 and 2002. The functionality of districts was measured using 13 indicators, with possible scores ranging from 0 to 13. District functionality with scores below 4.5 were classified as low, those above 9.5 were classified as high, while scores between these figures were considered moderate (see Table 6). At the end of 2004, four districts were categorised as 'low functionality', nine districts as 'moderate functionality' and four districts as 'high functionality'. Changes in functionality across the 17 participating districts between 2002 and 2004 ranged from -6 to +6 with three districts demonstrating significant improvement by moving into the high functionality category and four districts dropping into a lower category.

Table 6: Index scores of overall district functionality for 2004 (and 2002) 5

\begin{tabular}{lll}
\hline \multicolumn{1}{c}{ Low (0-4.4) } & \multicolumn{1}{c}{ Moderate (4.5-8.4) } & \multicolumn{1}{c}{ High (8.5-13) } \\
\hline & Moretele 7.95 (6.59) & \\
Johannesburg South Mega 3.50 (9.10) & Libode 7.88 (6.77) & \\
Zebediela 3.31 (4.09) & Western Cape Metro East 7.21 (5.49) & Karoo 11.99 (8.34) \\
Konekwena 2.36 (4.85) & Flagstaff 6.42 (3.89) & Thabo Mofutsanyana 11.38 (5.67) \\
Bolobedu 0.91 (5.08) & Lusikisiki 6.34 (3.26) & Sedibeng West 9.35 (10.29) \\
& Ubombo 5.89 (3.39) & \\
& Inanda 5.51 (7.49) & \\
& Mafikeng 5.46 (4.80) & \\
\hline
\end{tabular}

The results from the path analysis reveals that QLP interventions did affect the functioning of districts (especially during 2003/4), as well as functioning at other levels of the system; namely, schools and classrooms. It seems to be the case that in districts where there was effective forms of school support and monitoring, learner performance showed improvement. . The findings also suggests that increases in performance can partly be attributed to the interventions by districts, and other factors, especially those relating to efficiency of resource usage, which was applied by targeting interventions where the need was greatest.

The 'distance' between districts and classrooms/learners is perhaps still quite large, and the implementation of a district-based school-development model is still in its infancy. This situation, coupled with continued instability and restructuring, and large numbers of dysfunctional districts in some provinces, could explain the absence of larger or more immediate effects of interventions on the improvement of districts and learner performance. None the less, when all aspects have been weighed in, the fact that most of the individual indices and the overall functionality index improved from 2002 to 2004 represents an important outcome of this project.

\subsection{School-level functioning changes}

Changes in overall school functionality, also related to the years 2002 to 2004, are reported for both QLP and control schools. The QLP school development interventions focused on providing training in organisational development, management and governance. These interventions were directed mainly at School Governing Bodies (SGBs), principals and School Management Teams (SMTs). An overall school ranking was calculated by averaging all the main indices, that is, the preparedness of school principals for their jobs; the presence and availability of resources at schools; classroom adequacy (excluding class sizes, as too many missing values occurred in the data); effectiveness of curriculum

52002 scores indicated in brackets 
management; and school effectiveness in terms of administrative management and financial systems.

The index developed had a maximum score of 18 , with scores of $0-6.5$ classified as low functionality, $6.6-12.5$ rated moderate, and 12.6 - 18 high. Most schools fell within the moderate range. Change in scores for school-level functionality varied from -3 to +8 . As the detailed data review revealed, an increase in the monitoring of curriculum delivery in schools by the SMTs and heads of department (HODs) is evident, although the overall monitoring of curriculum delivery in most schools was still rated as moderate when the data was collected in 2004. The existence of learning programmes and syllabi and the monitoring of assessment practices were rated low for all schools. A composite index of curriculum management, covering aspects of curriculum monitoring, support and instructional leadership, showed some improvement, with the majority of schools achieving a moderate to high rating in 2004.

Figure 1: Average change in QLP and control school functionality by district.

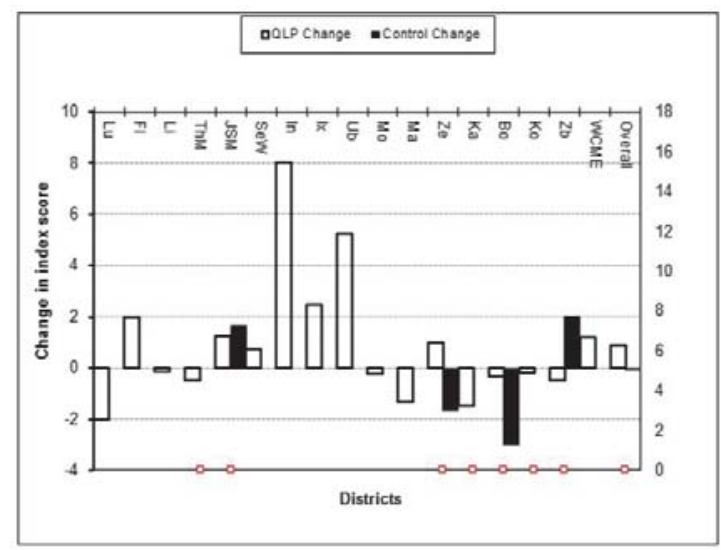

Information about both the QLP and control schools shows that overall school functioning improved by more than 10\% in QLP schools, while no change was observed in the control schools (see Figure 1). This difference can be attributed to the QLP interventions. The areas in which improvement in QLP schools was greater than that in control schools include the condition and provision of facilities, resources and infrastructure; the reduction of the negative effects of shortages of instructional materials on teaching and learning; needs-based teacher training and mentoring in terms of curriculum leadership; the existence and effective functioning of SGBs and SMTs; and the existence and effective use of records, especially for assets, learning materials, stockrooms and finances, as proof of effective school administration. All of these areas are consistent with the mandates given to QLP service providers for effecting improvement.

With regard to school management, which covered aspects of school development planning, management, finance, and administration, QLP schools showed a significant improvement, while scores for control-schools remained stable at moderate levels. The competency profiles of school principals in QLP schools, which reflect their management experience and highest qualifications, remained stable at a moderate level with respect to the index score. Resource levels in schools had initially been moderate, and improved in QLP-schools, but not in control schools. However, there were still great disparities regarding resource availability in schools across districts. Schools in Gauteng, Northern Cape and Western Cape districts were found to be better resourced than their counterparts in the Eastern Cape and Limpopo provinces. Despite improvements in resources in QLP schools, the results highlight the fact that many schools were still poorly provisioned.

Classroom adequacy, expressed mainly in terms of class size and the teacher-learner ratio, was found to have deteriorated over the years. There was a less marked deterioration in terms of shortages of classroom materials for teaching and learning. The control schools seemed to have deteriorated in terms of classroom adequacy and the effect of shortages of classroom materials on teaching and learning, suggesting that the QLP schools have experienced improved physical conditions because of the interventions. The composite index for support to teachers was rated moderate to high for more than half of the districts. However, as the technical report indicates, further support to schools is required in the Eastern Cape, North West and Limpopo provinces (Prinsloo and Kanjee, 2005). On the index for curriculum leadership, schools in nine of the 17 districts fell within the low category, indicating that a great deal of improvement is required in this area. In addition, the index for professional development indicated a widespread need for further intervention across schools in the various districts.

Overall, statistical modelling produced at least three sets of evidence pertaining to interventions' effects on system 
functioning. First, school functionality as defined above seemed to ensure good learner performance consistently. This could also signal a positive feedback 'loop' in terms of which good schools attract good learners who bring more accolades to the schools' performance and functioning. Second, QLP service providers efficiently targeted interventions where they were needed most. Third, teacher interventions seemed to be beneficial to school functioning, presumably through the use of acquired competencies in situations where school management skills were required.

\subsection{Classroom level functioning changes}

Once again, information on changes in classroom functioning from 2002 to 2004 is provided, as are the 2004 levels of functionality in grades 9 and 11, and by subject, in mathematics and language. Fifteen indices were constructed to measure the functionality of mathematics and language classes in the QLP and control schools, based on data obtained from teacher observations, interviews and questionnaires. For both subjects, changes in classroom functionality scores ranged from -8 to +18 . The total index score ranged from $0-64$, with $0-21.5$ being considered as low, $21.6-42.5$ as moderate, and 42.6 - 64 as high. An overall review of the data showed that, in general, mathematics functioning in grade 9 QLP classrooms improved more than in control schools while overall functionality levels in QLP schools ranged from moderate to high. However, for Grade 11 mathematics, QLP classrooms improved less than did the control schools. Turning to language, the data shows that the functioning of grade 9 QLP classrooms improved slightly more than that of control-schools with levels ranging from moderate to high. Similarly, Grade 11 language classroom functioning improved slightly less in QLP classrooms than it did in control schools.

In general, QLP schools outperformed control schools in terms of classroom functionality in mathematics. For example, with regard to grade 9 activities, improvements included lesson pedagogy, assessment and improved class work. With respect to grade 11 activities, factors such as curriculum coverage, assignment of class work, and homework contributed towards improving the mathematics index score over time. With regard to reading and writing in both grades, QLP schools often outperformed the control schools in terms of classroom functionality over time. For grade 9 activities, such improvements included curriculum coverage, the cognitive skills demanded by the lesson, lesson pedagogy and class work. At grade 11 level, aspects of classroom functionality such as curriculum coverage and class work impacted positively on the index scores.

\section{Capturing Patterns of Interaction between and among Interventions and Effects}

A systematic and comprehensive path analysis exercise (Arbuckle, 2006) was conducted to capture effects emerging from interactions, between and among, the various program interventions applied to various modes of functioning at district, school and classroom levels. One point of interest for this analysis was of course learner performance and matriculation results. The path analysis also captured the 'legacy effects' from programme interventions during 20002001 which influenced and shaped the programme interventions during 2002-2004. The seven diagrammatic presentations of the path analyses included standardized path weights for modeling causal patterns for learner performance in (i) grade 9 mathematics; (ii) grade 9 language; (iii) grade 11 mathematics; (iv) grade 11 language; (v) matriculation results; (vi) matriculation English results; and (vii) matriculation mathematics results (See Kanjee \& Prinsloo, 2005 for additional details).

Schools in which learners in grades 9 and 11 were enrolled in mathematics and language programmes had obtained higher scores in 2002. They maintained their higher performance levels in 2004. This is also true for overall matriculation pass rates and mathematics grade 12 pass rates. There is consistency and stability in intervention levels and system functioning over time. This finding signals that once critical mass and impetus are achieved, it is not too difficult to sustain them. The evaluation study confirms that the effective functioning of districts, schools and classrooms had a positive impact on learner performance. The transfer of effects from year to year (from 2002 to 2004) in terms of interventions, functionality and learner performance, signals stability in the sense of continuous resource allocation and effort in the same specific locations. The fact that teacher interventions predicted school functionality could be ascribed to the application of newly developed skills by teachers in improving the functioning of classrooms and schools. For mathematics at grade 11 level, district interventions predicted learner performance in the 2003/4 period indicating that direct interventions by districts can improve learner performance. These findings provide specific information with regard to the approach and focus required to improve ailing education systems, or parts of them, quickly. 


\section{Conclusion}

The results of the evaluation reported in the paper notes that between 2000 and 2004 QLP schools showed significant improvement in learner performance across both subjects areas. As discussed this can be attributed to focused support by service-providers to those schools that needed the most assistance, effective monitoring and support by district officers as well as school managers, improved school functioning driven by good classroom and teacher interventions, and greater resourcing and improved teacher functioning at the classroom level. . The results of the evaluation show that well-structured and effectively delivered interventions can enhance the quality of learning. However, limited infrastructure and capacity in the education system in some districts, and hasty efforts at restructuring are risks that jeopardise sustained progress.

From the review of the QLP a number of important lessons for improving education quality emerge. First, the findings point to the need for policy makers to adopt comprehensive approaches to school development, sustaining and enhancing the program benefits, based on sound theoretical principles. Second, interventions to improve teaching and learning must be integrated and coherent, earn the support and commitment of participants through appropriate engagement, and should target the earlier stages of school life rather than focus on matriculation learners. Third, at district and school levels, managers should sustain their efforts to manage their school support and monitoring roles focusing specifically on providing visionary supervision, mentorship, and leadership. In particular, district officers should support teaching and learning at schools by producing relevant, practical, and high quality learning content underpinned by solid foundational knowledge. Similarly, school management teams should nurture the professional development of their teachers through good mentoring and motivation as well as sound management and curriculum leadership. In this regard, the provision of adequate numbers of excellent teacher trainers and mentors has to be prioritized. Classroom teachers should be supported to ensure they maximize on teaching time and curriculum coverage, while there should be continual stress on issues pertaining to improved content expertise of teachers, teacher-learner interactions, discipline, and the provision of sufficient facilities and learning materials.

The evaluation of the QLP suggests that large-scale education reform to improve education is daunting but possible. In the QLP, both the intervention and evaluation were designed collaboratively by stakeholders - policy makers, planners, implementers, and evaluators making it an effective approach to system change. While the QLP has made a significant difference to improving learning and teaching, and its impact was limited to participating districts and schools, the lessons learnt can contribute to the quest to provide good quality for all in South Africa. However, this remains a major challenge that will require a more coherent and strategic large-scale focus that address the specific needs of schools, teachers and learners. To this end, evaluations of large scale education interventions of the kind reported in this paper will enable researchers, policy-makers, and practitioners to obtain a more informed and evidence based understanding of what makes a difference in improving education quality, and thus be in a better position to develop relevant interventions to improve education quality for all in South Africa

\section{References}

Arbuckle, J. L. (2006). Amos (Version 7.0) [Computer Program]. Chicago: SPSS.

Bhola, H.S. (1998). They are learning and discerning: Evaluation of an adult education project of the National Literacy Co-operation of South Africa. Studies in Educational Evaluation, 24 (4):153-177.

Bhola, H.S. (2002). A model and method of evaluative accounts: Development impact of the National Literacy Mission (NLM) of India. Studies in Educational Evaluation, 28 (3): 273296.

DDSP/RTI. (2003). Improving the quality of primary education. Pretoria: DDSP/RTI.

Department of Education (DoE), Republic of South Africa. (1997). Curriculum 2005: Lifelong learning for the 21 Century. Pretoria: Department of Education.

ECDoE (2000) Enabling transformation and renewal: The Imbewu model for school development and transformation. East London: Eastern Cape Department of Education

Kanjee, A. \& Prinsloo, C. (2005). Improving learning in South African schools: The Quality Learning Project - Summative evaluation. Cape Town: HSRC Press.

Meyer S. (2000). Philosophical and theoretical underpinnings of EQUIP, Unpublished report, Johannesburg: National Business Initiative

Mouton, J. (1999). The Thousand Schools Project: Evaluating a whole school development initiative. In Donald, D; Dawes, A and Louw, J (eds.). Addressing childhood adversity. Cape Town: David Philip Publishers.

Prew, M. \& Shar, S. (2013). The Quality Learning Project: An Integrated Theory-Driven Intervention. In Y. Sayed, A. Kanjee, \& Nkomo, $\mathrm{M}$ (eds.). The search for quality education in post-apartheid South Africa: Interventions to improve learning and teaching. (pp 210-229) Cape Town: HSRC Press.

Prinsloo, C. \& Kanjee, A. (2005). Improving learning in South African schools: The Quality Learning Project - Technical Report. Cape 
Town: HSRC Press.

Republic of South Africa. (1995). South African Qualifications Authority Act 58 of 1995.

Republic of South Africa. (1996a). The Constitution of the Republic of South Africa 1996. One law for one nation as adopted by the Constitutional Assembly May 8, 1996 and as amended 11 October 1996.

Republic of South Africa. (1996b). National Education Policy Act of 1996 (No. 27 of 1996)

Schollar, E (2008). The Learning for Living Projec,2000 - 2004: A book-based approach to the learning of language in South African primary schools. University of Stellenbosch: CSSR Working Paper No. 233.

Sayed, Y., Kanjee, A., \& Nkomo, M. (2013). The search for quality education in post-apartheid South Africa: Interventions to improve learning and teaching. Cape Town: HSRC Press.

Shavelson, R., McDonnell, L. \& Oakes, J. (eds.) (1989). Indicators for monitoring mathematics and science education: A sourcebook. Santa Monica, CA Rand. 